\title{
Mudas de Mangue Branco Irrigadas com Água de Rejeito de Salina Solar em Substrato Areia de Restinga para Replantio de Manguezais Degradados
}

\section{White Mangrove Seedlings Irrigated with Solar Saltworks Bittern in Restinga Sand Substrate for Replanting Degraded Mangrove Areas}

\author{
Sílvio Roberto Fernandes Soares ${ }^{\mathrm{a}}$; Marcelo Tavares Gurgel ${ }^{\mathrm{b}}$; Neyton de Oliveira Miranda*b; Kaline Dantas Travassosª \\ Alexandre Santos Pimenta ${ }^{\mathrm{c}}$
${ }^{a}$ Universidade Federal Rural do Semi-Árido, Programa de Pós-Graduação Stricto Sensu em Manejo de Solo e Água. RN, Brasil.

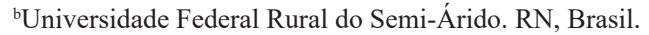
'Universidade Federal do Rio Grande do Norte. RN, Brasil.
*E-mail: neyton.miranda@ufersa.edu.br

\begin{abstract}
Resumo
A necessidade de repovoar áreas de mangue degradadas pela produção de sal marinho levantou a questão da viabilidade da produção de mudas de mangue branco (Laguncularia racemosa (L.) C. Gaertn) com água e substrato obtidos próximos aos manguezais. Para tanto, foram testados o substrato Areia de Restinga e suas misturas com proporções de 25 e $50 \%$ de fibra de coco, bem como irrigação com água doce ou água contendo $5 \%$ e $10 \%$ de água de rejeito de salina com alta concentração de sal (água-mãe). O delineamento experimental foi o inteiramente casualizado em esquema fatorial, os dados foram analisados por meio da análise de variância e as médias foram comparadas pelo teste de Tukey. As avaliações foram realizadas em cinco períodos de desenvolvimento de plântulas e incluíram massa seca total, altura de planta, diâmetro de caule, massa seca da parte aérea, massa seca da raiz e índice de qualidade de Dickson. O substrato de areia de restinga e a irrigação com água doce proporcionaram as melhores dimensões e qualidade das mudas de mangue branco, mas mudas de tamanho e qualidade muito próximos foram produzidas quando a água aplicada continha $5 \%$ da água salgada. Os resultados obtidos serão aplicados para a produção de mudas de mangue branco, economizando água de boa qualidade e reduzindo custos com substrato comercial.
\end{abstract}

Palavras-chave: Degradação Ambiental. Viveiro Florestal. Ambiente Salino.

\begin{abstract}
The need to repopulate mangrove areas degraded by sea salt production has raised the question of the viability of producing white mangrove (Laguncularia racemosa (L.) C. Gaertn) seedlings with water and substrate obtained near the mangroves. Therefore, the substrate Restinga Sand and its mixtures with proportions of 25 and 50\% of coconut fiber were tested, as well as irrigation with freshwater or water containing $5 \%$ and $10 \%$ saltworks brine with high salt concentration (bittern). The experimental design was completely randomized in a factorial scheme. Data analysis consisted of variance analysis and Tukey Test for comparison of means. Evaluations carried out in five periods of seedling development included total dry mass, plant height, stem diameter, shoot dry mass, root dry mass, and Dickson quality index. Restinga Sand substrate and irrigation with freshwater provided the best dimensions and quality of white mangrove seedlings, but seedlings of very close size and quality were produced when the applied water contained $5 \%$ of the saltworks bittern. The obtained results will be applied to produce white mangrove seedlings saving good quality water and reducing costs with commercial substrate.
\end{abstract}

Keywords: Environmental Degradation. Forest Nursery. Saline Environment.

\section{Introdução}

A produção de sal marinho em salinas solares gera impostos e empregos para muitas famílias e, por isso, contribui significativamente para a economia do Rio Grande do Norte (ROCHA et al., 2012), localizado na região Nordeste do Brasil. O Estado produziu 5,8 milhões de toneladas de sal no ano de 2016, enquanto a produção brasileira foi de 6,0 milhões de toneladas (BRASIL, 2019). A produção de sal marinho é uma das causas da degradação dos ecossistemas de mangues no litoral deste Estado. Por isto, a modernização desta atividade deve aliar a melhoria da qualidade do seu produto com preocupações ambientais de proteção e recuperação de áreas degradadas (COSTA et al., 2013).

No litoral do Nordeste Brasileiro se encontram ao redor de $10 \%$ dos manguezais do país, que ocorrem em lagunas, lagamares e na foz dos principais rios. Os manguezais do Rio Grande do Norte ocorrem em toda faixa litorânea e possuem uma área de 12.451 ha, dos quais apenas 16,3\% são protegidos (PRATES et al., 2012). A ameaça representada pelo processo de produção de sal nas salinas solares é o uso de grande quantidade de água do mar e a geração de água hipersalina como subproduto. Por isso, uma grande preocupação ambiental é destinar adequadamente esta água, que possui grande quantidade de magnésio, de potássio e outros elementos que, se extraídos, têm potencial de uso na indústria e como fertilizante na agricultura (ROCHA et al., 2012; SHAHMANSOURI et al., 2012).

Os manguezais são muito importantes do ponto de vista ecológico e socioeconômico e são altamente produtivos. Sua taxa de produção primária é igual a das florestas tropicais úmidas perenes e dos recifes de corais. Por isso, têm grande capacidade de sequestro do dióxido de carbono atmosférico (ALONGI, 2014; ABRANTES et al., 2015). Entre os serviços proporcionados pelos manguezais é possível citar: ecoturismo; 
habitat para moluscos, crustáceos, aves, insetos, primatas e répteis; local de parada de aves migratória; berçário para diversas espécies marinhas; local de pesca costeira, aeração de sedimentos; proteção costeira e manutenção da profundidade do canal de cursos de água (EL-REGAL; IBRAHIM, 2014; ABRANTES et al., 2015; BLOTTA et al., 2016).

Apesar de Spalding et al. (2010) terem quantificado a taxa de devastação dos manguezais do mundo em 3\% a 4\% ao ano, maior que a taxa de desmatamento em ecossistemas terrestres, Friess et al. (2019) afirmam que estas taxas não são mais tão altas e têm diminuído globalmente. Entretanto, os manguezais continuam sendo devastados em todas as regiões, principalmente, em países como Mianmar e Malásia, nos quais as taxas de desmatamento são crescentes. No Brasil, apesar das leis de proteção, a ação humana tem papel central na destruição de áreas de manguezais por meio de atividades econômicas de alto impacto como o turismo, desmatamento para a extração de madeira e lenha, especulação imobiliária, construção civil, atividades agropecuárias, como a carcinicultura, represamento de rios, poluição por falta de saneamento básico e por lançamento de resíduos sólidos em aterros sanitários (MEDEIROS et al., 2015; SILVA; MAIA, 2018).

O processo de recuperação dos mangues é baseado, principalmente, na produção de mudas para replantio, pois as espécies nativas não geram sementes em quantidade e qualidade adequadas ao repovoamento natural. Segundo Kodikara et al. (2018), mudas de mangue produzidas em viveiros são geralmente irrigadas com água doce, sem a preocupação com a salinidade da água, e transplantadas para os mangues com poucos meses de idade. $\mathrm{O}$ índice de mortalidade destas mudas após o transplante está ao redor de $70 \%$. Entre as causas de mortalidade está o efeito osmótico que as mudas irrigadas com água doce sofrem ao serem expostas ao ambiente salino.

Por isso, é recomendado que a produção de mudas de mangue seja feita em viveiros com características da água de irrigação e do substrato semelhantes aos encontrados no ambiente do mangue no qual serão transplantadas (SCREMIN-DIAS et al., 2006; COSTA, 2015; OLIVEIRA et al., 2016), pois a qualidade das mudas determina o potencial de sobrevivência, crescimento no campo e sucesso do plantio.

O objetivo deste trabalho foi avaliar a qualidade das mudas da espécie Laguncularia racemosa (L.) C. F. Gaertn utilizando-se água de rejeito de salina e substrato de areia de restinga obtidos em áreas próximas a manguezais.

\section{Material e Métodos}

A produção das mudas foi realizada em casa de vegetação do Centro de Ciências Agrárias da Universidade Federal Rural do SemiÁrido, em Mossoró, RN, Brasil (5¹2' S, 37²19' W), no período de 23 de setembro de 2015 a 3 de fevereiro de 2016. O clima da região é do tipo BSwh, segundo a classificação de Köppen.

A casa de vegetação possui orientação Norte-Sul e foi construída em estrutura de alvenaria e ferro com piso não pavimentado. A cobertura em arco é composta por filme de polietileno de baixa densidade com aditivo anti-ultravioleta e espessura de 150 micras. As laterais são protegidas por malha negra com sombreamento de $50 \%$.

Os tipos de água de irrigação usados no experimento foram preparados pela mistura de água doce (AD) com água proveniente de bacias de cristalização (AS) da Salina Miramar, em Areia Branca, RN (4'56’43” S, 3707'13” W). As proporções utilizadas foram: A1: $100 \% \mathrm{AD}, \mathrm{A} 2: 95 \% \mathrm{AD}$ $+5 \%$ AS, A3: $90 \%$ AD + 10\% AS. Os substratos usados no experimento foram preparados pela mistura de areia de restinga (AR) com fibra de coco (FC), nas seguintes proporções: $\mathrm{S} 1$ : 100\% AR, S2: $50 \%$ AR + 50\% FC, e S3: 75\% AR + 25\% FC. A areia foi obtida em uma Restinga próxima à Salina Miramar. As características dos substratos e das águas empregadas no estudo (Quadro 1) foram determinadas de acordo com metodologias apresentadas em Donagema et al. (2011).

Quadro 1 - Características das águas de irrigação e dos substratos usados na montagem dos experimentos de avaliação de qualidade de mudas de mangue branco

\begin{tabular}{|c|c|c|c|c|c|c|c|c|c|}
\hline \multirow{2}{*}{ Substrato } & \multirow{2}{*}{$* \mathrm{pH}$} & ${ }^{*} \mathrm{CE}$ & $* \mathrm{Na}^{+}$ & ${ }^{*} \mathrm{~K}^{+}$ & ${ }^{*} \mathrm{Ca}^{2+}$ & $* \mathrm{Mg}^{2+}$ & Areia & Silte & Argila \\
\hline & & $\left(\mathrm{dS} \mathrm{m} \mathrm{m}^{-1}\right)$ & \multicolumn{4}{|c|}{$\left(\mathrm{cmol}_{\mathrm{c}} \mathrm{kg}^{-1}\right)$} & \multicolumn{3}{|c|}{$\left(\mathrm{kg} \mathrm{kg}^{-1}\right)$} \\
\hline S1 & 8,3 & 1,65 & 310 & 43 & 7 & 34 & 0,94 & 0,02 & 0,4 \\
\hline S2 & 7,5 & 2,64 & 518 & 2289 & 11 & 1543 & 0,84 & 0,13 & 3,4 \\
\hline S3 & 7,7 & 2,65 & 670 & 729 & 13 & 483 & 0,93 & 0,03 & 0,8 \\
\hline \multirow[t]{2}{*}{ Água } & $\mathrm{pH}$ & $\mathrm{CE}$ & Baumé & \multicolumn{2}{|c|}{$\mathrm{Na}^{+}$} & \multicolumn{2}{|c|}{$\mathrm{K}^{+}$} & $\mathrm{Ca}^{2+}$ & $\mathrm{Mg}^{2+}$ \\
\hline & & $\left(\mathrm{dS} \mathrm{m} \mathrm{m}^{-1}\right)$ & (grau) & \multicolumn{6}{|c|}{$\left(\mathrm{mg} \mathrm{L}^{-1}\right)$} \\
\hline A1 & 8,60 & 0,5 & 0 & \multicolumn{2}{|c|}{88} & \multicolumn{2}{|c|}{27} & 20 & 79 \\
\hline $\mathrm{A} 2$ & 7,60 & 29,6 & 2 & \multicolumn{2}{|c|}{2527} & \multicolumn{2}{|c|}{430} & 64 & 283 \\
\hline A3 & 7,54 & 54,2 & 4 & \multicolumn{2}{|c|}{4675} & \multicolumn{2}{|c|}{850} & 132 & 675 \\
\hline
\end{tabular}

*Estas características foram determinadas na pasta do extrato de saturação. CE - Condutividade elétrica. S1: 100\% Areia de Restinga (AR), S2: 50\% $\mathrm{AR}+50 \%$ fibra de coco (FC), e S3: $75 \% \mathrm{AR}+25 \% \mathrm{FC}$. A1: $100 \%$ água doce (AD), A2: $95 \% \mathrm{AD}+5 \%$ água salina (AS); e A3: $90 \% \mathrm{AD}+10 \% \mathrm{AS}$. Fonte: Dados da pesquisa.

Os recipientes empregados para a produção das mudas de mangue branco foram sacos plásticos de polietileno com altura de $25 \mathrm{~cm}$ e volume de aproximadamente de 0,57 L. Depois de preenchidos com os substratos, os sacos foram lavados com $3 \mathrm{~L}$ de água doce $\left(0,5 \mathrm{dS} \mathrm{m}^{-1}\right)$, visando uniformizar a condutividade elétrica do substrato. 
As sementes de Laguncularia racemosa (L.) C.F.Gaertn foram coletadas em manguezal localizado no município de Icapuí-CE $\left(4^{\circ} 41^{\prime} 28.0^{\prime \prime} \mathrm{S} \quad 37^{\circ} 21^{\prime} 13.5^{\prime \prime} \mathrm{W}\right)$, onde a vegetação apresenta condições semelhantes às originais. Em 23 de setembro de 2015, foram semeadas duas sementes por saco em profundidade ao redor de $1,0 \mathrm{~cm}$. O desbaste foi realizado aos 40 dias após a semeadura, mantendo-se uma plântula em cada saco. Em caso de não haver emergência em algum dos sacos, procedeu-se a repicagem das plântulas dentro da própria parcela.

A irrigação foi realizada duas vezes ao dia com água doce $\left(0,5 \mathrm{dS} \mathrm{m}^{-1}\right)$ até 28 dias após a semeadura, para garantir a germinação das sementes. Após este período, realizou-se a aplicação dos tratamentos e as mudas passaram a ser irrigadas diariamente com as proporções de água correspondentes aos tratamentos. A partir daí foram contados os intervalos entre as amostragens em dias após a aplicação dos tratamentos (DAT).

$\mathrm{O}$ delineamento experimental adotado foi em blocos casualizados, em esquema fatorial, no qual os fatores estudados foram os tipos de água e os tipos de substrato. $\mathrm{O}$ experimento era constituído por quatro blocos com 36 parcelas e 25 plantas por parcela, totalizando 900 unidades experimentais. Os sacos foram colocados em suportes acima do solo com espaçamento de $1,0 \times 0,8 \mathrm{~m}$.

Os tratamentos constaram da combinação dos três tipos de água de irrigação $\left(\mathrm{A} 1=0,5 \mathrm{dS} \mathrm{m}^{-1}, \mathrm{~A} 2=29,6 \mathrm{dS} \mathrm{m}^{-1}\right.$, e A3 = $\left.54,2 \mathrm{dS} \mathrm{m}^{-1}\right)$ com três tipos de substrato ( $\mathrm{S} 1=100 \% \mathrm{AR}, \mathrm{S} 2=$ $50 \% \mathrm{AR}+50 \% \mathrm{FC}$, e S3 $=75 \% \mathrm{AR}+25 \% \mathrm{FC}$ ).
As medidas foram realizadas aos 21, 42, 63, 84 e 105 dias após a aplicação dos tratamentos (DAT), quando foram retiradas três plantas uniformes de cada parcela e foram determinadas: MST - Massa seca total, em g; AP - Altura da planta, em mm; DC - Diâmetro de caule, em mm; MSPA - Massa seca da parte aérea, em g e MSR - Massa seca da raiz, em g. Essas medidas foram usadas para calcular o IQD - Índice de qualidade de Dickson (DICKSON et al., 1960), conforme a Equação 1. Também foi determinado o número de folhas por planta (NF).

$$
\mathrm{IQG}=\frac{\mathrm{MST}}{\left(\frac{\mathrm{AP}}{\mathrm{DC}}\right)-\left(\frac{\mathrm{MSPA}}{\mathrm{MSR}}\right)}
$$

As variáveis NF, DC, AP e IQD foram submetidas à análise de variância pelo teste $\mathrm{F}(\mathrm{p}<0,05)$ em cada data de amostragem. Nos casos de efeito significativo, as médias foram comparadas pelo teste de Tukey $(\mathrm{p}<0,05)$, utilizando-se o software SISVAR 5.6 (FERREIRA, 2014).

\section{Resultados e Discussão}

As variáveis de crescimento e de qualidade de mudas de mangue branco foram influenciadas pelo tipo de água de irrigação, em quase todas as datas de amostragem, com exceção de AP aos 21, 42 e 63 DAT. Por sua vez, o tipo de substrato não influenciou o DC aos 21 e 42 DAT, nem AP aos 21 DAT e nem IQD aos 21, 42 e 63 DAT. O efeito da interação entre o tipo de água e o tipo de substrato sobre NF somente não foi observado aos 21 DAT, mas foi observado sobre AP aos 84 e 105 DAT e sobre DC e IQD somente aos 105 DAT (Quadro 2).

Quadro 2 - Resumo da análise da variância de Número de Folhas, Diâmetro do Caule, Altura de Planta e Índice de Qualidade de Dickson de Mudas de mangue branco irrigadas com água de rejeito de salina solar em dois substratos

\begin{tabular}{|c|c|c|c|c|c|c|}
\hline Causas de Variação & GL & 21 DAT & 42 DAT & 63 DAT & 84 DAT & 105 DAT \\
\hline & \multicolumn{6}{|c|}{ Número de Folhas (quadrados médios) } \\
\hline Água (A) & 2 & $0,95^{* *}$ & $6,61^{* *}$ & $16,85^{* *}$ & $26,36^{* *}$ & $30,71^{* *}$ \\
\hline Substrato (S) & 2 & $1,36^{* *}$ & $8,23^{* *}$ & $20,01^{* *}$ & $60,57^{* *}$ & $83,48^{* *}$ \\
\hline $\mathrm{AxS}$ & 4 & $0,26^{\mathrm{ns}}$ & $3,03^{* *}$ & $5,35^{* *}$ & $11,19^{* *}$ & $14,87^{* *}$ \\
\hline Bloco & 3 & $0,72^{* *}$ & $0,05^{\mathrm{ns}}$ & $0,60^{\text {ns }}$ & $0,42^{\text {ns }}$ & $0,56^{\mathrm{ns}}$ \\
\hline \multirow[t]{2}{*}{ Resíduo } & 24 & 0,17 & 0,37 & 0,67 & 0,40 & 0,74 \\
\hline & \multicolumn{6}{|c|}{ Diâmetro do Caule (quadrados médios) } \\
\hline Água (A) & 2 & $0,23^{* *}$ & $0,56^{* *}$ & $0,45^{* *}$ & $0,66^{* *}$ & $1,26^{* *}$ \\
\hline Substrato (S) & 2 & $0,01^{\mathrm{ns}}$ & $0,02^{\text {ns }}$ & $0,14^{* *}$ & $0,55^{* *}$ & $1,22^{* *}$ \\
\hline $\mathrm{AxS}$ & 4 & $0,01^{\mathrm{ns}}$ & $0,02^{\mathrm{ns}}$ & $0,01^{\mathrm{ns}}$ & $0,06^{\mathrm{ns}}$ & $0,19^{* *}$ \\
\hline Bloco & 3 & $0,02^{\mathrm{ns}}$ & $0,03^{\text {ns }}$ & $0,06^{*}$ & $0,08^{\mathrm{ns}}$ & $0,02^{\text {ns }}$ \\
\hline \multirow[t]{2}{*}{ Resíduo } & 24 & 0,03 & 0,02 & 0,02 & 0,04 & 0,03 \\
\hline & \multicolumn{6}{|c|}{ Altura de Planta (quadrados médios) } \\
\hline Água (A) & 2 & $0,57^{\mathrm{ns}}$ & $0,41^{\mathrm{ns}}$ & $0,17^{\mathrm{ns}}$ & $6,65^{* *}$ & $10,83^{* *}$ \\
\hline Substrato (S) & 2 & $0,40^{\mathrm{ns}}$ & $1,46^{*}$ & $10,21^{* *}$ & $26,41^{* *}$ & $62,13^{* *}$ \\
\hline $\mathrm{AxS}$ & 4 & $0,13^{\mathrm{ns}}$ & $0,31^{\mathrm{ns}}$ & $1,65^{\mathrm{ns}}$ & $8,84^{* *}$ & $15,76^{* *}$ \\
\hline Bloco & 3 & $1,02^{\mathrm{ns}}$ & $1,17^{* *}$ & $0,47^{\mathrm{ns}}$ & $0,67^{\text {ns }}$ & $0,63^{\text {ns }}$ \\
\hline \multirow[t]{2}{*}{ Resíduo } & 24 & 0,45 & 0,41 & 0,48 & 0,37 & 0,79 \\
\hline & \multicolumn{6}{|c|}{ Índice de Qualidade de Dickson (quadrados médios) } \\
\hline Água (A) & 2 & $0,0043^{* *}$ & $0,01392^{* *}$ & $0,0182^{* *}$ & $0,00995^{*}$ & $0,0429^{* *}$ \\
\hline Substrato $(\mathrm{S})$ & 2 & $0,0016^{\mathrm{ns}}$ & $0,00017^{\mathrm{ns}}$ & $0,0018^{\mathrm{ns}}$ & $0,02924^{* *}$ & $0,0549^{* *}$ \\
\hline $\mathrm{AxS}$ & 4 & $0,0006^{\mathrm{ns}}$ & $0,00187^{\mathrm{ns}}$ & $0,0017^{\mathrm{ns}}$ & $0,00084^{\mathrm{ns}}$ & $0,0071^{* *}$ \\
\hline Bloco & 3 & $0,0012^{\text {ns }}$ & $0,00051^{\mathrm{ns}}$ & $0,0049^{\text {ns }}$ & $0,00361^{\mathrm{ns}}$ & $0,0013^{\text {ns }}$ \\
\hline Resíduo & 24 & 0,0006 & 0,0010 & 0,0010 & 0,00224 & 0,0006 \\
\hline
\end{tabular}

DAT: dias após a aplicação dos tratamentos; GL= graus de liberdade; ** Significativo a $1 \%$ de probabilidade pelo teste F; * Significativo a $5 \%$ de probabilidade pelo teste $\mathrm{F}$; ${ }^{\text {ns }}$ não significativo. 
Fonte: Dados da pesquisa.

A aplicação de água doce (A1) proporcionou os maiores valores para as variáveis e datas de amostragem, que foram influenciadas pelo tipo de água de irrigação individualmente. Os menores valores foram obtidos quando foi aplicada a água mais salina (A3), que continha $10 \%$ de água de rejeito de salina. $\mathrm{Na}$ maioria das vezes, a água de salinidade intermediária (A2), que

continha $5 \%$ deágua de rejeito de salina, proporcionou valores estatisticamente semelhantes aos valores obtidos comaáguaA1 (Quadro 3).

Quadro 3 - Comparação de médias entre fatores de tipo de água e tipo de substrato tomados individualmente sobre variáveis de crescimento e qualidade de mudas de mangue branco

\begin{tabular}{|c|c|c|c|c|c|c|c|}
\hline & \multicolumn{4}{|c|}{ Tipo de Água } & \multicolumn{3}{|c|}{ Tipo de substrato } \\
\hline & A1 & A2 & A3 & & S1 & $\mathbf{S 2}$ & S3 \\
\hline & \multicolumn{3}{|c|}{$21 \mathrm{DAT}$} & & \multicolumn{3}{|c|}{$21 \mathrm{DAT}$} \\
\hline NF & $3,60 \mathrm{~A}$ & $3,40 \mathrm{~A}$ & $3,03 \mathrm{~B}$ & NF & $3,67 \mathrm{~A}$ & $2,97 \mathrm{~B}$ & $3,40 \mathrm{~A}$ \\
\hline $\mathrm{DC}$ & $1,83 \mathrm{~A}$ & $1,77 \mathrm{~A}$ & $1,57 \mathrm{~B}$ & - & - & - & - \\
\hline \multirow[t]{2}{*}{ IQD } & $0,14 \mathrm{~A}$ & $0,10 \mathrm{~B}$ & $0,10 \mathrm{~B}$ & - & - & - & - \\
\hline & \multicolumn{3}{|c|}{ 42DAT } & & \multicolumn{3}{|c|}{42 DAT } \\
\hline $\mathrm{DC}$ & $2,30 \mathrm{~A}$ & $2,10 \mathrm{AB}$ & $1,87 \mathrm{~B}$ & AP & $6,70 \mathrm{~A}$ & $6,27 \mathrm{~B}$ & $6,03 \mathrm{C}$ \\
\hline \multirow[t]{2}{*}{ IQD } & $0,18 \mathrm{~A}$ & $0,16 \mathrm{~A}$ & $0,13 \mathrm{~B}$ & - & - & - & - \\
\hline & \multicolumn{3}{|c|}{63 DAT } & & \multicolumn{3}{|c|}{63 DAT } \\
\hline $\mathrm{DC}$ & $2,23 \mathrm{~A}$ & $2,23 \mathrm{~A}$ & $1,87 \mathrm{~B}$ & $\mathrm{DC}$ & $2,23 \mathrm{~A}$ & $2,13 \mathrm{~A}$ & $1,97 \mathrm{~B}$ \\
\hline \multirow[t]{2}{*}{ IQD } & $0,18 \mathrm{~A}$ & $0,18 \mathrm{~A}$ & $0,12 \mathrm{~B}$ & $\mathrm{AP}$ & $7,40 \mathrm{~A}$ & $6,30 \mathrm{~B}$ & $5,57 \mathrm{C}$ \\
\hline & \multicolumn{3}{|c|}{84 DAT } & & \multicolumn{3}{|c|}{ 84 DAT } \\
\hline $\mathrm{DC}$ & $2,43 \mathrm{~A}$ & $2,23 \mathrm{AB}$ & $2,00 \mathrm{~B}$ & $\mathrm{DC}$ & $2,47 \mathrm{~A}$ & $2,13 \mathrm{~B}$ & $2,07 \mathrm{~B}$ \\
\hline IQD & $0,19 \mathrm{~A}$ & $0,17 \mathrm{~A}$ & $0,13 \mathrm{~B}$ & IQD & $0,22 \mathrm{~A}$ & $0,13 \mathrm{~B}$ & $0,13 \mathrm{~B}$ \\
\hline
\end{tabular}

NF: número de folhas; DC: diâmetro do caule (mm); AP: altura de planta $(\mathrm{cm})$; IQD: índice de qualidade de Dickson; DAT: dias após a aplicação dos tratamentos. S1: 100\% Areia de Restinga (AR), S2: 50\% AR + 50\% fibra de coco (FC), e S3: 75\% AR + 25\% FC. A1: 100\% água doce (AD), A2: 95\% $\mathrm{AD}+5 \%$ água salina (AS); e A3: $90 \% \mathrm{AD}+10 \% \mathrm{AS}$. Médias seguidas por letras maiúsculas iguais nas linhas não diferem quanto ao efeito dos fatores

salinidade da água e proporção de substrato pelo Teste de Tukey $(\mathrm{p}<0,05)$.

Fonte: Dados da pesquisa.

O substrato contendo $100 \%$ de Areia de Restinga (S1) proporcionou os maiores valores para as variáveis e datas de amostragem, que foram influenciadas pelo tipo de substrato individualmente. Entretanto, nas datas analisadas, os valores das variáveis não permitiram estabelecer uma diferença clara entre os substratos que continham fibra de coco (Quadro 3).
$\mathrm{O}$ substrato $\mathrm{S} 1$, recebendo tanto a água $\mathrm{A} 1$ como a água $\mathrm{A} 2$, proporcionou os maiores valores das variáveis que foram influenciadas pela interação entre o tipo de água de irrigação e o tipo de substrato em todas as datas de amostragem (Quadro 4). Em alguns casos, não foi observada diferença significativa quando se usou A1 ou A2, como em DC aos 42 DAT e AP, $\mathrm{CD}$ e IQD aos 105 DAT. Também foi verificada uma grande superioridade das combinações de $\mathrm{S} 1$ com A1 e de S1 com A2 em relação às outras combinações. Por outro lado, os menores

valores das variáveis foram observados predominantemente quando se usou a água A3 com qualquer um dos substratos, sem ser observada diferença significativa entre os substratos.

Quadro 4 - Desdobramento das interações significativas entre nível de salinidade da água de irrigação e proporção dos substratos sobre variáveis de crescimento e qualidade de mudas de mangue branco

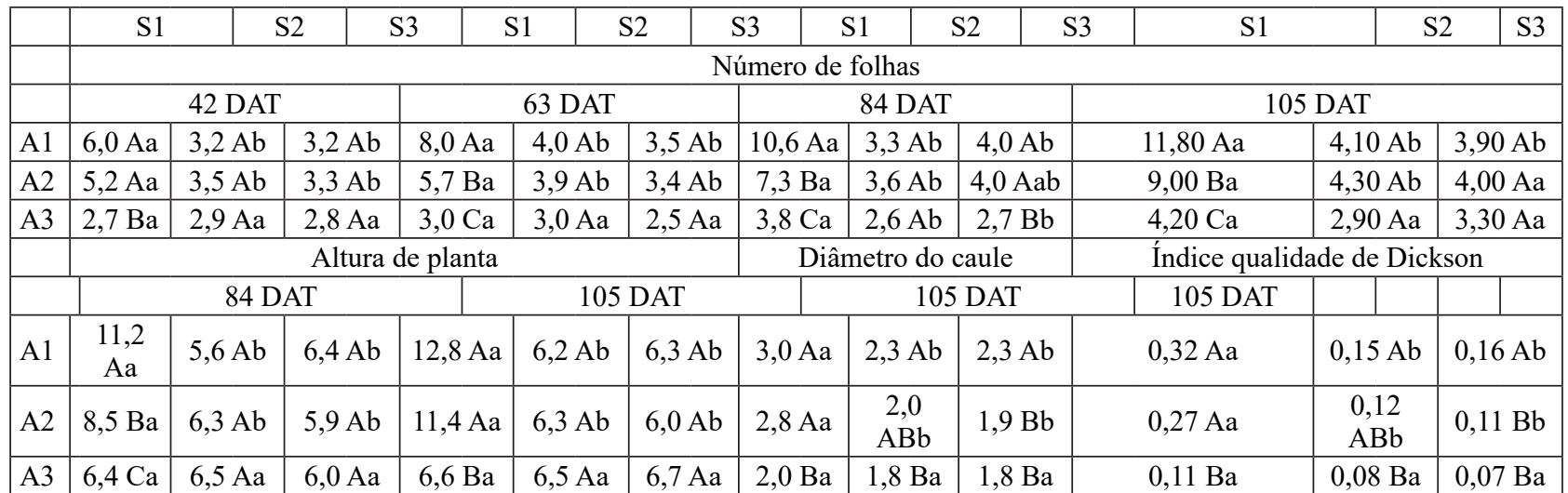

DAT: dias após a aplicação dos tratamentos. S1: $100 \%$ Areia de Restinga (AR), S2: $50 \%$ AR + 50\% fibra de coco (FC), e S3: $75 \%$ AR + 25\% FC. A1: $100 \%$ água doce (AD), A2: 95\% AD + 5\% água salina (AS); e A3: $90 \% \mathrm{AD}+10 \% \mathrm{AS}$. Médias seguidas por letras maiúsculas iguais nas colunas

não diferem quanto ao efeito do fator salinidade da água pelo Teste de Tukey $(\mathrm{p}<0,05)$. Médias seguidas por letras minúsculas iguais nas linhas não diferem quanto ao efeito do fator proporção dos substratos pelo Teste de Tukey $(\mathrm{p}<0,05)$. 
Fonte: Dados da pesquisa.

Os maiores valores das variáveis obtidos quando foi aplicada água doce em todas as datas de amostragem eram esperados e estão de acordo com estudo de Kodikara et al. (2018), no qual a água doce proporcionou melhor estabelecimento, desenvolvimento inicial e taxa de sobrevivência de mudas de mangue. Mesmo em ambiente salino, Bompy et al. (2014) observaram melhoria duradoura da fotossíntese e da produção de biomassa do mangue branco em função da aplicação ocasional de água doce.

Por outro lado, os menores valores das variáveis estudadas foram observados quando a água aplicada continha $10 \%$ de água de rejeito de salina $\left(54,2 \mathrm{dS} \mathrm{m}^{-1}\right)$. Isso indica que a elevada concentração de sais na água de irrigação causa estresse e prejudica o desenvolvimento das plantas em decorrência do acúmulo de sais no substrato e consequente diminuição do potencial osmótico e efeito tóxico de alguns íons nas células (GARCIA et al., 2008).

O efeito osmótico em função da diminuição do potencial hídrico externo prejudica a absorção de água e nutrientes pelas raízes e o efeito tóxico afeta diretamente os sistemas enzimáticos e de membranas. $\mathrm{O}$ íon $\mathrm{Na}^{+}$está envolvido neste processo e promove efeitos negativos sobre a capacidade das plantas em absorver, transportar e utilizar nutrientes (EPSTEIN; BLOOM, 2006; GHEYI et al., 2010).

As mudas de espécies de mangue respondem à salinidade excessiva por meio da diminuição no número e taxa de crescimento das folhas, reduzindo assim a área foliar (MUNNS; TESTER, 2008; CUNHA et al., 2013; COSTA, 2015). Segundo Wu e Cosgrove (2000), é comum que as plantas alterem a relação de crescimento das raízes em relação da parte aérea por meio de ajuste osmótico, que mantém a pressão de turgor nas células da raiz. Isso também foi observado em plantas de mangues por Reef e Lovelock (2015).

Em geral, plantas sob condições de alta salinidade acumulam sais em excesso nas células foliares e apresentam redução na fotossíntese. A menor divisão celular, redução na formação de novas células, e menor taxa de alongamento celular promovem a formação mais lenta de folhas, as quais são menores e mais espessas. $\mathrm{O}$ crescimento das plantas é inibido em decorrência do prejuízo ao desenvolvimento da gema apical, atrofia dos ramos, diminuição da área folhar, amarelecimento e necrose das folhas (EPSTEIN; BLOOM, 2006; GARCIA et al., 2008; KANAI et al., 2014; COSTA, 2015).

Uma observação interessante deste trabalho é que, em geral, a água contendo 5\% de água de rejeito de salina proporcionou resultados semelhantes aos valores obtidos com a água A1. Neste aspecto, Kodikara et al. (2018) comentam que algumas espécies de mangue apresentam seu melhor crescimento sob condições de salinidade moderada. Em seu trabalho, os autores observaram o pior estabelecimento inicial, crescimento e sobrevivência de mudas de espécies de mangue produzidas sob alta salinidade do que sob salinidade baixa ou moderada. Entretanto, ao longo do tempo, as mudas produzidas sob salinidade moderada se adaptaram à salinidade e superaram o desempenho das produzidas sob baixa salinidade. Isto demonstra que a tolerância de plantas de mangue às condições de salinidade depende da espécie e da idade e está relacionada à eficiência de uso da água.

A possibilidade de irrigar mudas de mangue com água de salinidade moderada proporciona economia de água doce. Isso foi demonstrado em diferentes estudos realizados em regiões nas quais não existe água doce suficiente para a irrigação, mas existem águas salobras, que podem ser misturadas. Isso permite a irrigação de áreas maiores, mas não diminui o total dos sais nas águas de irrigação. Em estudo de Barbosa et al. (2012), a irrigação com água doce de forma alternada com água salina $\left(5 \mathrm{dS} \mathrm{m}^{-1}\right)$ proporcionou economia de $50 \%$ de água de boa qualidade sem prejudicar a produtividade do milho. Esta estratégia deve evitar o uso de água salina nos estágios mais sensíveis de desenvolvimento das plantas, como emergência e crescimento inicial. Outra estratégia consiste na mistura de água doce com a água salina (SILVA et al., 2014). Quando estes autores realizaram a mistura visando obter água com EC de 2,75 dS m ${ }^{-1}$ conseguiram economizar 43,3\% de água doce com pequenos prejuízos para as culturas do milho e sorgo.

Outro aspecto suscitado pelos resultados obtidos com água de salinidade moderada é que as mudas produzidas com este nível de salinidade $\left(29,6 \mathrm{dS} \mathrm{m}^{-1}\right)$, ao serem transplantadas para o campo, terão maiores chances de se estabelecerem e sobreviverem nos ambientes salinos do que as mudas produzidas com água doce. Isso seria uma maneira de aclimatar as mudas ao ambiente salino ainda no viveiro. Neste sentido, Bompy et al. (2014) estudaram três espécies de mangue, entre as quais o mangue branco. Os autores observaram mortalidade de mudas, crescimento e trocas de gases pelas folhas e concluíram que o aumento da salinidade até condições de salinidade moderada induziu a aclimatação e melhorou a tolerância do mangue branco aos sais.

É importante ressaltar que as mudas foram cultivadas em recipientes, que é um meio mais limitante às raízes do que o solo, e no qual a acumulação de sais na zona radicular é mais pronunciada quando a irrigação é realizada com água salina (VALDÉS et al., 2014). Nesse sentido, ficou bem demonstrado pelos resultados obtidos que o substrato mais adequado foi a areia de restinga, que é obtida em ambiente natural próximo aos manguezais. Segundo Cavalcante et al. (2009), em substrato arenoso, o acúmulo de sais é menor e o crescimento das plantas é menos inibido em função de seu maior espaço poroso, que permite maior movimento de ar e água. Os autores observaram que o crescimento e qualidade das mudas de maracujazeiro amarelo irrigados com água salina foram mais prejudicados no substrato mais argiloso. 
Alguns autores alertam para problemas de salinidade em substratos baseados em fibra de coco por apresentar lixiviação insuficiente. Em estudo de Depardieu et al. (2016) ocorreu maior acumulação de sais e aumento na condutividade elétrica neste substrato em relação a outros substratos. Além disso, Valdés et al. (2014) ressaltam ser mais provável a acumulação de sais na parte superior do recipiente contendo fibra de coco. Isso ocorre porque este substrato seca mais rapidamente na superfície do que em profundidade. Por isso, é gerado um déficit de pressão que causa o movimento da água para a parte superior do substrato e a aceleração da evaporação.

A análise da interação entre os fatores estudados indica que o comportamento das mudas foi melhor quando se associou o substrato areia de restinga com a água doce ou com a água contendo 5\% de água de rejeito de salina, principalmente aos 105 DAT, ou seja, quando as plântulas estavam prontas para o plantio, a maioria das variáveis indicou como melhor opção o uso do substrato $\mathrm{S} 1$ com a possibilidade de usar tanto a água A1 como a água A2.

Nesse aspecto, pode ser uma boa estratégia produzir as mudas próximo ao local de plantio, como em áreas de mangues degradados, com benefícios de facilidade de acesso ao substrato e à água salina e economia com transporte. $\mathrm{O}$ sucesso do replantio de mudas de mangue para a restauração de área degradada é maior se a coleta de sementes ou propágulos e a produção de mudas forem realizadas na mesma área ou em locais com características ambientais semelhantes às da área a ser reflorestada (SCHAEFFER-NOVELLI et al., 1990; ARAÚJO et al., 2014). Nesse sentido, Menéndez et al. (2002) afirmam que a produção de mudas próximo ao ambiente natural de mangue é uma forma de produzir mudas de maior qualidade e que elevar com antecedência a salinidade da água simula o ambiente de mangue.

\section{Conclusão}

O substrato de areia de restinga e a irrigação com água doce proporcionaram as melhores dimensões e qualidade das mudas de mangue branco, mas mudas de tamanho e qualidade muito próximos foram produzidas quando a água aplicada continha $5 \%$ da água salgada. Os resultados obtidos serão aplicados na produção de mudas de mangue branco, economizando água de boa qualidade e reduzindo custos com substrato comercial.

\section{Referências}

ABRANTES, K.G. et al. Importance of mangrove carbon for aquatic food webs in wet-dry tropical estuaries. Estuar. Coast., v.38, n.1, p.383-399, 2015. doi: 10.1007/s12237-014-9817-2

ALONGI, D.M. Carbon cycling and storage in mangrove forests. Ann. Rev. Mar. Sci., v. 6, n.1, p.195-219, 2014. doi: 10.1146/ annurev-marine-010213-135020

ARAÚJO, E.C. et al. Qualidade das mudas de espécies arbóreas de mangue cultivadas em viveiro e diferentes substratos. Acta Ambient. Catarin., v.11, n.1/2, p.21-32, 2016. doi: 10.24021/raac. v11i1/2.3091
BARBOSA, F.S. et al. Yield and ion content in maize irrigated with saline water in a continuous or alternating system. Cienc. Rural., v.42, n.10, p.1731-1737, 2012. doi: 10.1590/S010384782012001000003

BLOTTA, K.D. et al. Fitossociologia comparativa de dois manguezais: Canal de Bertioga/SP e do estuário da Barra do Rio Una-Peruíbe-SP. Unisanta BioScience, v.5, n.3, p.271-282, 2016.

BOMPY, F. et al. Increasing fluctuations of soil salinity affect seedling growth performances and physiology in three Neotropical mangrove species. Plant Soil, v.380, n.1/2, p.399413, 2014. doi: 10.1007/s11104-014-2100-2

BRASIL. Agencia Nacional de Mineração. Sumario Mineral 2017. Brasília: ANM, 2019.

CAVALCANTE, L.F. et al. Crescimento inicial do maracujazeiro amarelo manejado em dois substratos irrigados com água salina. Irriga, v.14, n.4, p.504-517, 2009. doi: 10.15809/ irriga.2009v14n4p504-517

COSTA, D.F. et al. Breve revisão sobre a evolução histórica da atividade salineira no estado do Rio Grande do Norte (Brasil). Soc. \& Nat., v.25, n.1, p.21-34, 2013.

COSTA, L.R. Uso de águas hipersalinas na produção de mudas de mangue. Mossoró: Universidade Federal Rural do SemiÁrido, 2015.

CUNHA, P.C. et al. Crescimento, síntese de solutos orgânicos e equilíbrio iônico de plântulas de pinhão-manso sob estresse salino. Rev. Caatinga, v.26, n.3, p.46-52, 2013.

DEPARDIEU, C. et al. Sawdust and bark-based substrates for soilless strawberry production: irrigation and electrical conductivity management. PLOS ONE, v.11, n.4, e0154104, 2016. doi: 10.1371/journal.pone.0154104

DICKSON, A.; LEAF, A.L.; HOSNER, J. F. Quality appraisal of white spruce and white pine seedling stock in nurseries. Florest Chron., v.36, n.1, p.10-13, 1960. doi: 10.5558/tfc36010-1

DONAGEMA, G.K. et al. Manual de métodos de análise de solos. Rio de Janeiro: Embrapa Solos, 2011.

EL-REGAL, M.A.A.; IBRAHIM, N.K. Role of mangroves as a nursery ground for juvenile reef fishes in the southern Egyptian Red Sea. Egypt. J. Aquat. Res., v. 40, n.1, p.71-78, 2014. doi: 10.1016/j.ejar.2014.01.001

EPSTEIN, E.; BLOOM, A.J. Nutrição mineral de plantas: princípios e perspectivas. Londrina: Editora Planta, 2006.

FERREIRA, D.F. Sisvar: a Guide for its Bootstrap procedures in multiple comparisons. Cienc. Agrotec., v.38, n.2, p.109-112, 2014. doi: 10.1590/S1413-70542014000200001

FRIESS, D. A. et al. The state of the world's mangrove forests: past, present, and future. Annu. Rev. Environ. Resour., v.44, n.1, p.89-115, 2019. doi: 10.1146/annurev-environ-101718-033302

GARCIA, G.O. et al. Alterações químicas de dois solos irrigados com água salina. Rev. Cienc. Agron., v.39, n.1, p.7-18, 2008.

GHEYI, H. R.; DIAS, N. DA S.; LACERDA, C. F. de. Manejo da salinidade na agricultura: estudos básicos e aplicados. Fortaleza: INCTSal, 2010.

KANAI, H.; TAJIMA, M.; SAKAI, A. Effects of salinity on the growth and survival of the seedlings of mangrove, Rhizophora stylosa. Int. J. Plant Soil Sci., v.3, n.7, p.879-893, 2014. doi: 10.9734/IJPSS/2014/9812 
KODIKARA, K.A.S. et al. The effects of salinity on growth and survival of mangrove seedlings changes with age. Acta Bot. Bras., v.32, n.1, p.37-46, 2018. doi: 10.1590/0102-33062017abb0100

MEDEIROS, S.R.M.; CARVALHO, R.G.; PIMENTA, M.R.C. A proteção do ecossistema manguezal a luz da lei: 12.651/2012: novos desafios para a sustentabilidade dos manguezais do Rio Grande do Norte. Rev. Geotemas, v.4, n.2, p.59-78, 2015.

MENÉNDEZ, L.; GUZMÁN, J.M.; CAPOTE-FUENTES, R.T. Bases ecológicas para la restauración del ecosistema de manglar en el archipiélago cubano. In: CARRERA, L.M.; GUZMÁN, J.M. Ecosistemas de manglar en el archipiélago cubano. Cuba: Editorial Academia, 2002.

MUNNS, R.; TESTER, M. Mechanisms of salinity tolerance. Annu. Rev. Plant Biol., v.59, p.651-681, 2008. doi: 10.1146/ annurev.arplant.59.032607.092911

OLIVEIRA, M.C. et al. Manual de viveiro e produção de mudas: espécies arbóreas nativas do Cerrado. Brasília: Rede de Sementes do Cerrado, 2016.

PRATES, A.P.L.; GONÇALVES, M.A.; ROSA, M.R. Panorama da conservação dos ecossistemas costeiros e marinhos no Brasil. 2012. Disponível em: http://www.mma.gov.br/ estruturas/205/ publicacao/205_publicacao030220111 00749.pdf. Acesso em: $1 \overline{6}$ ago. 2019.

ROCHA, R.D.M. et al. Brazilian solar saltworks-ancient uses and future possibilities. Aquat. Biosyst., v.8, n.1, p.8, 2012.

REEF, R; LOVELOCK, C.E. Regulation of water balance in mangroves. Ann. Bot., v.115, n.3, p.385-395, 2015. doi: 10.1093/ aob/mcu174
SCHAEFFER-NOVELLI, Y. et al. Variability of mangrove ecosystems along the Brazilian coast. Estuaries, v.13, n.2, p.204$218,1990$.

SCREMIN-DIAS, E. et al. Produção de mudas de espécies florestais nativas: manual. Campo Grande: UFMS, 2006.

SILVA, J.L.A. et al. Uso de águas salinas como alternativa na irrigação e produção de forragem no semiárido nordestino. Rev. Bras. Eng. Agric. Ambient., v.18, p.S66-S72, 2014. doi: 10.1590/1807-1929/agriambi.v18nsupps66-s72

SILVA, N.R; MAIA, R.C. Avaliação do tamanho e peso de propágulos das espécies pioneiras de mangue na formação de plântulas para a recuperação de manguezais. Gaia Scie., v.12, n.3, p.117-128, 2018. doi: 10.22478/ufpb.1981$1268.2018 \mathrm{v} 12 \mathrm{n} 3.39306$

SHAHMANSOURI, A. et al. Feasibility of extracting valuable minerals from desalination concentrate: a comprehensive literature review. J. Clean. Prod., v.100, p.4-16, 2015. doi: 10.1016/j.jclepro.2015.03.031

SPALDING, M.; KAINUMA, M.; COLLINS, L. World atlas of mangroves. Abingdon, UK: Routledge, 2010.

VALDÉS, R. et al. The number of emitters alters salt distribution and root growth in potted gerbera. Hortscience, v.49, n.2, p.160165. 2014. doi: 10.21273/HORTSCI. 49.2.160

WU, Y.; COSGROVE, D.J. Adaptation of roots to low water potentials by changes in cell wall extensibility and cell wall proteins. J. Exp. Bot., v.51, n.350, p.1543-1553, 2000. doi: $10.1093 /$ jexbot $/ 51.350 .1543$ 